\title{
Etnomatematika Pada Bentuk Jajanan Pasar di Daerah Istimewa Yogyakarta
}

\author{
Nuk Tohul Huda \\ Pendidikan Matematika USD, Sleman Yogyakarta; nuktohulhuda@gmail.com
}

Dikirim: 28 Desember 2017; Diterima: 5 September 2018; Dipublikasikan: 25 September 2018 Cara sitasi: Huda, N.T. 2018. Etnomatematika Pada Bentuk Jajanan Pasar Di Daerah Istimewa Yogyakarta. JNPM (Jurnal Nasional Pendidikan Matematika) Vol. 2(2), Hal. 217-232.

\begin{abstract}
Abstrak. Daerah Istimewa Yogyakarta merupakan daerah yang kental dengan berbagai tradisi. Makanan tradisional seperti Jajanan pasar adalah salah satu syarat yang biasanya digunakan dalam prosesi tradisi tersebut. Misalnya sesaji, prosesi pernikahan, orang meninggal, grebeg maulud tidak terlepas dari unsur makanan tradisional. Jajanan pasar adalah makanan tradisional yang kita jumpai di pasar-pasar tradisional dan merupakan makanan warisan leluhur, tetapi saat ini sudah berkembang menjadi makanan yang dapat kita jumpai dipusat perbelanjaan modern. Penelitian ini bertujuan untuk mengetahui bentuk-bentuk geometri dalam aneka jajanan pasar, serta unsur-unsur matematis terkait. Menggunakan pendekatan etnomatematika peneliti melakukan eksplorasi dan mengelompokkan aneka bentuk jajanan pasar berdasarkan unsur bangun datar dan bangun ruang pada materi Sekolah. Penelitian ini berbentuk dekriptif kualitatif. Poses pengambilan data dilakukan dengan kajian literatur, studi lapangan dan wawancara dengan beberapa sumber terkait. Unsur-unsur matematis yang ditemukan dalam penelitian ini cukup banyak secara geometris ditemukan bentuk bidang datar segi empat, lingkaran, segitiga, trapezium, elips, sedangkan untuk bangun ruang ditemukan diantaranya bentuk bola, silinder, balok, kerucut. Secara ekonomis berdasarkan proses pembuatan dan penjualannya juga ditemukan bentuk model matematika persamaan linear 2 dan 3 variabel. Hasil dari penelitian ini diharapkan akan memberi manfaat bagi pembelajaran kontekstual dan digunakan sebagai contoh penggunaan konsep matematika disekitar kita.
\end{abstract}

Kata kunci: Etnomatematika, Jajanan Pasar, unsur matematis

Abstract. Yogyakarta Special Region is a thick area with various traditions. Traditional food such as Jajanan market is one of the conditions usually used in the procession of the tradition. For example 
offerings, wedding processions, people died, grebeg maulud can not be separated from traditional food elements. Market snacks are traditional foods that we find in traditional markets and are ancestral food, but nowadays it has evolved into food we can find in modern shopping centers. This study aims to determine the forms of geometry in various market snacks, as well as mathematical elements related. Using an ethnormatic approach the researcher explores and classifies various forms of market snacks based on the elements of wake up and wake up space on the School material. This research is in the form of qualitative decriptive. The data collection poses were conducted with literature review, field study and interviews with several related sources. The mathematical elements found in this research are quite geometrically found in the form of rectangular plane, circle, triangle, trapezium, ellipse, while for waking space is found among them the shape of the ball, cylinder, beam, cone. Economically based on the process of manufacture and sale also found the form of mathematical models of linear equations 2 and 3 variables. The results of this study are expected to provide benefits for contextual learning and are used as examples of the use of mathematical concepts around us.

Keywords: Ethnomathematics, Market snacks, element of mathematics.

\section{Pendahuluan}

Jajanan pasar yang ada di Indonesia merupakan ciri khas budaya beraneka ragam, baik berupa kue kering maupun kue basah beserta modifikasinya. Sesuai dengan namanya, awalnya jajanan pasar dijual di pasar tradisional. Dengan perkembangannya, jajanan pasar kini menjadi terkenal. Daerah istimewa Yogyakarta merupakan bagian dari tanah jawa yang kaya akan aneka ragam budaya dan tradisi leluhur. Tradisi turun menurun tersebut terwujud dalam berbagai aspek misalnya, kesenian, pendidikan, ekonomi, arsitektur, termasuk makanan keseharian. Pada jenis makanan yang paling dekat kita kenal adalah jajanan pasar. Makanan ini sudah merambah kemana-mana di pinggir-pinggir jalan, di pasar sendiri dan bahkan sampai ke toko-toko swalayan. Berbagai macam kegiatan seperti rapat, seminar hajatan juga tidak lepas dari suguhan snack makanan jajanan pasar.

Secara fisik dari bentuk makanan ini memiliki ciri khas dengan corak dan bentuk yang hampir selalu sama sejak zaman dahulu. Misalnya saja ondeonde (bulat), klepon (bulat), kue lapis (kotak), lemper (silinder) dan berbagai jenis makanan yang lainnya. Sekilas ketika diperhatikan lebih jauh tentunya 
bentuk tersebut adalah bagian dari geometri dalam matematika. Agar lebih mendalam penulis disini akan mengkaji keterkaitan setiap bentuk jenis makanan jajanan pasar dengan unsur matematikanya, serta sejarah kenapa muncul bentuk-bentuk tersebut.

Menurut tradisi dan kebudayaan yang berkembang khususnya di tanah jawa, pada beberapa bentuk dan nama dari makanan tradisional yang dijadikan syarat dalam setiap ritual tradisi memiliki makna secara filosofis kejawen. Misalnya bentuk tumpeng, secara filosofis memiliki arti dari bentuk manusia yang sangat banyak hanya sedikit yang mampu mencapai kepada sang pencipta, ini sesuai dengan bentuknya yang berbentuk kerucut, lebar di atas dan lancip atau mengecil pada puncaknya. Tentunya beberapa Jajanan pasar atau makanan tradisional yang lain juga banyak memiliki maknamakna yang lain dengan unsur budaya yang sangat kental.

Kajian bidang geometri merupakan bagian dari kurikulum pendidikan yang diajarkan dari tingkat SD sampai perguruan tinggi. Mendalami beberapa bentuk geometri yang terdapat dalam fisik jajanan pasar untuk dikaitkan dengan pembelajaran geometri SD tentunya akan sangat menarik. Siswa dengan tuntutan dari kurikulum 2013 untuk memperkenalkan pendidikan lebih bermanfaat bagi lingkungan sekitar, dapat diajak bereksplorasi mempelajari berbagai bentuk geometri Jajanan pasar tersebut. Sehingga diharapkan hasil dari penelitian ini juga akan dapat memberikan kegunaan untuk pembelajaran matematika misalnya geometri SD dan beberapa materi matematika terkait yang lainnya. Tujuan penelitian mengetahui jenis-jenis jajanan pasar apa saja yang terdapat di wilayah Daerah Istimewa Yogyakarta. Mengetahui bentuk budaya apa saja yang banyak menggunakan jajanan pasar sebagai bagian dari tradisi masyarakat di wilayah Daerah Istimewa Yogyakarta. Mengetahui aspek- aspek matematis apa saja yang terdapat dalam berbagai bentuk jajanan pasar di Wilayah Daerah Istimewa Yogyakarta.

\section{Metode Penelitian}

Penelitian ini merupakan penelitian deskriptif kualitatif, menggunakan metode studi lapangan, wawancara dan studi dokumen untuk mendapatkan data yang valid. Setelah data diperoleh kemudian dianalisis dan diolah menggunakan sistem pengelompokkan sesuai dengan kategori dan unit-unit JNPM (Jurnal Nasional Pendidikan Matematika) Vol. 2, No. 2, Hal. 217-232 p-ISSN 2549-8495, e-ISSN 2549-4937 @Prodi Pendidikan Matematika Unswagati Cirebon 
berdasarkan masing-masing pola unsur matematika yang ditemukan yaitu berdasarkan kelompok geometri bidang datar dan geometri ruang. Hasil tersebut kemudian dilakukan analisis dan penarikan kesimpulan.

\section{Hasil dan Pembahasan}

Etnomatematika adalah matematika yang diterapkan oleh kelompok budaya tertentu, kelompok buruh atau petani, anak-anak dari masyarakat kelas tertentu, kelas-kelas profesional, dan lain sebagainya (Gerdes, 1994). Dari definisi seperti ini, maka etnomatematika memiliki pengertian yang lebih luas dari hanya sekedar etno (etnis) atau suku. Mengapa etnomatematika menjadi disiplin ilmu dan menjadi perhatian luas akhir-akhir ini. Salah satu alasan yang bisa dikemukakan adalah karena pengajaran matematika di sekolah memang terlalu bersifat formal. Hiebert \& Capenter (1992), mengingatkan kepada semua pihak bahwa pengajaran matematika di sekolah dan matematika yang ditemukan anak dalam kehidupan sehari-hari sangat berbeda. Oleh sebab itu pembelajaran matematika sangat perlu memberikan muatan untuk menjembatani antara matematika dalam dunia sehari-hari yang berbasis pada budaya lokal dengan matematika sekolah.

Istilah etnomatematika berasal dari kata ethnomathematics, yang diperkenalkan oleh D'Ambrosio seorang matematikawan dari Brasil pada tahun 1977. Terbentuk dari kata ethno,mathema, dan tics. Awalan ethno mengacu pada kelompok kebudayaan yang dapat dikenali, seperti perkumpulan suku di suatu negara dan kelas-kelas profesi di masyarakat, termasuk pula bahasa dan kebiasaan mereka sehari-hari. Kemudian, mathema disini berarti menjelaskan, mengerti, dan mengelola hal-hal nyata secara spesifik dengan menghitung, mengukur, mengklasifkasi, mengurutkan, dan memodelkan suatu pola yang muncul pada suatu lingkungan. Akhiran tics mengandung arti seni dalam teknik. Secara istilah etnomatematika diartikan sebagai matematika yang dipraktikkan di antara kelompok budaya diidentifkasi seperti masyarakat nasional suku, kelompok buruh, anak-anak dari kelompok usia tertentu dan kelas professional (D'Ambrosio, 1985: 4448). Lebih luas lagi, jika ditinjau dari sudut pandang riset, maka etnomatematika didefnisikan sebagai antropologi budaya (cultural 
antrophology of mathematics) dari matematika dan pendidikan matematika (D'Ambrosio, 2006: 1)

Gagasan etnomatematika akan dapat memperkaya pengetahuan matematika yang telah ada. Oleh sebab itu, jika perkembangan etnomatematika telah banyak dikaji maka bukan tidak mungkin matematika diajarkan secara bersahaja dengan mengambil budaya setempat. Menurut Bishop (1994b), matematika merupakan suatu bentuk budaya. Matematika sebagai bentuk budaya, sesungguhnya telah terintegrasi pada seluruh aspek kehidupan masyarakat dimanapun berada. Pada hakekatnya matematika merupakan teknologi simbolis yang tumbuh pada ketrampilan atau aktivitas lingkungan yang bersifat budaya. Dengan demikian matematika seseorang dipengaruhi oleh latar belakang budayanya, karena yang mereka lakukan berdasarkan apa yang mereka lihat dan rasakan. Budaya akan mempengaruhi perilaku individu dan mempunyai peran yang besar pada perkembangan pemahaman individual, termasuk pembelajaran matematika (Bishop, 1991).

Masyarakat adalah kesatuan hidup dari makhluk-makhluk manusia yang terikat oleh suatu sistem adat istiadat (Koentjaraningrat, 1996: 100). Masyarakat Jawa merupakan salah satu masyarakat yang hidup dan berkembang mulai zaman dahulu hingga sekarang yang secara turuntemurun menggunakan bahasa jawa dalam berbagai ragam dialeknya dan mendiami sebagian besar Pulau Jawa (Herusatoto, 1987: 10). Di Jawa sendiri selain berkembang masyarakat Jawa juga berkembang masyarakat Sunda, Madura, dan masyarakat-masyarakat lainnya. Pada perkembangannya masyarakat Jawa tidak hanya mendiami Pulau Jawa, tetapi kemudian menyebar di hampir seluruh penjuru nusantara. Bahkan di luar Jawa pun banyak ditemukan komunitas Jawa akibat adanya program transmigrasi yang dicanangkan pemerintah. Masyarakat Jawa ini memiliki karakteristik tersendiri dibandingkan dengan masyarakat-masyarakat lainnya, seperti masyarakat Sunda, masyarakat Madura, masyarakat Minang, dan lain sebagainya.

Masyarakat Jawa sangat kental dengan nilai tradisi dan kearifan lokal. Melalui berbagai macam bentuk upacara atau ritual kearifan lokal ini mereka wujudkan sebagai bentuk kepercayaan dan pengahayatan kepada yang maha pencipta. Di dalam kearifan lokal tersebut termuat berbagai sikap dan JNPM (Jurnal Nasional Pendidikan Matematika) Vol. 2, No. 2, Hal. 217-232 p-ISSN 2549-8495, e-ISSN 2549-4937 @Prodi Pendidikan Matematika Unswagati Cirebon 
etika moralitas yang bersifat religius juga mengenai ajaran spiritualitas kehidupan manusia dengan alam semesta. Beberapa tradisi yang sampai sekarang masih bertahan misalnya Mitoni, Sepasaran, Wetonan, kelahiran, Khitanan, Mantu, Ruwatan, Peringatan kemerdekaan (tirakatan), Sadranan, Bersih desa, Sekaten (grebeg Maulid), peringatan orang meninggal mulai dari tujuh hari, empat puluh hari sampai seribu hari.

Istilah jajanan itu sendiri merupakan suatu jenis makanan tadisional yang biasa dimakan sehari-hari, namun bukan merupakan makanan pokok. Kita sering mendengar kata Jajan yang artinya membeli sesuatu sebagai selingan. Sedangkan ketika digabungkan antara Jajanan Pasar maka dapat diartikan sebagai makanan tradisional atau Jajanan yang biasa dijual di pasar. Hal ini menjadi umum karena sampai saat ini kita banyak melihat hampir disetiap pasar menjumpai jenis makanan sebagai jajanan. Jajanan pasar Indonesia yang ada di tanah air kita merupakan ciri khas budaya beraneka ragam jajanan pasar merupakan kue tradisional beserta modifikasinya, baik berupa kue kering maupun kue basah. Sesuai dengan namanya, awalnya jajanan pasar dijual di pasar tradisional. Di Indonesia sendiri, pembuatan jajanan pasar seperti kue basah maupun kering sudah tidak asing dalam menggunakan bahan baku tepung beras. Tepung beras yaitu tepung yang terbuat dari beras yang digiling atau ditumbuk sampai halus. Di pasaran tersedia dua macam tepung beras, yaitu tepung beras yang segar karena baru ditumbuk dan lembab karena masih terdapat kandungan airnya, serta tepung beras buatan pabrik yang memiliki umur simpan lebih lama.

\section{Unsur Geometri}

\section{Lingkaran}

Putu ayu pada bagian atas dan bawahnya berbentuk lingkaran, bagian tengahnya yang bolong juga merupakan bentuk lingkaran. Diameter lingkaran tengahnya sekitar $1 \mathrm{~cm}$ sedangkan untuk total lingkaran luar diameternya $6 \mathrm{~cm}$.

Kue lumpur pada permukaan bagian atas dan bawahnya juga merupakan bentuk lingkaran, keu ini dicetak menggunakan cetakan yang disebut 
dengan loyang dengan banyak bentuk lingkaran-lingkaran kecil. Adapun ukuran lingkaran pada kue ini berdiameter sama yaitu $7 \mathrm{~cm}$.

Srabi solo secara bentuk mirip dengan kue lumpur, makanan ini juga dibuat dengan menggunakan cetakan yang berbentuk lingkaran-lingkaran. Bagian bawah atau dalamnya memiliki diameter $5 \mathrm{~cm}$ dan luarnya atau yang atas 7 $\mathrm{cm}$.

Kue cucur pada bagian permukaannya juga berbentuk lingkaran, karena makanan ini juga dibuat menggunakan cetakan yang berbentuk lingkaran. Ukuran diameter lingkaran kue ini lebih besar daripada cetakannya karena sedikit mengalami pengembangan setelah digoreng, dengan diameter sekitar $7-8 \mathrm{~cm}$.

Donat, makanan ini juga memiliki unsur lingkaran dibagian tengah atau yang bolong dan bagian keseluruhannya. Ukurannya cukup banyak ada yang kecil sedang dan besar, karena membuatnya tidak dengan cetakan tapi menggunakan tangan dan kemudian digoreng sehingga ukurannya berkembang dari sebelum dengan sesudah matang. Untuk donat kecil (donat kentang) ukuran lingkaran dalamnya berdiameter $2 \mathrm{~cm}$ dan luarnya berdiameter $6-7 \mathrm{~cm}$.

Kue pia / bakpia, Kue ini juga dibuat manuat dengan tangan, tidak dicetak tetapi hasilnya berbentuk lingkaran pada atas dan bawahnya walaupun lingkarannya tidak halus. Ukuran bakpia yang kecil diameternya sekitar 4 $\mathrm{cm}$.

Bika ambon ekonomis, dibuat menggunakan cetakan yang berbentuk lingkaran sehingga hasilnya juga berbentuk lingkaran pada bagian bawah dan atasnya. Diameter lingkarannya sama yaitu $6 \mathrm{~cm}$.

Apem nasi, makanan dibuat dengan menggunakan cetakan yang bagian atas dan bawahnya berbentuk lingkaran. Bentuknya seperti mangkuk kecil jadi lingkaran bawah dan atas tidak sama, besar lingkaran atasnya. Diameter lingkaran yang bawah $3 \mathrm{~cm}$ dan yang atas $4 \mathrm{~cm}$.

Kue carabikang, bentuk lingkaran pada kue ini pada bagian atasnya tidak rata, sedangkan pada bagian bawah karena tertutup kertas pembungkus maka bentuk lingkarannya cukup jelas dengan diameter $5 \mathrm{~cm}$. 


\section{Bola (Bulat)}

Klepon, makanan ini berbentuk seperti kelereng kecil-kecil biasanya ditaruh dengan alas kertas atau daun yang menyerupai lingkaran juga dengan jumlah sekitar 5 - 9 buah per tempatnya. Ukuran diameter luarnya $2 \mathrm{~cm}$ yang dapat luas permukaan dari klepon atau bola yaitu $4 \pi \mathbf{r}^{2}$ dengan $r=1$, maka luas permukaan klepon $4 \pi$. Sedangkan volumenya $\frac{4}{3} \pi \mathbf{r}^{3}$ dengan $r=1$, maka volume klepon $\frac{4}{3} \pi$.

Onde-onde, bentuk yang sudah sangat fimilier dikita dengan unsur bulat atau bola melekat pada makanan ini. Ukuran diameter dari onde-onde sekitar 4 $\mathrm{cm}$ atau $\mathrm{r}=2 \mathrm{~cm}$. Maka dapat dihitung luas permukaan laur dari onde-onde $4 \pi r^{2}$ dengan $r=2$ hasilnya $16 \pi$. Sedangkan volumenya $4 / 3 \pi r^{3}$ dengan $r=2$, maka volume onde-onde $\frac{32}{3} \pi$.

Grontol, makanan ini merupakan hasil olahan dari jagung atau biji jagung dengan ukuran biji jagung yang agak bulat kecil-kecil. Ukuran diameternya sekitar $1 \mathrm{~cm}$ atau $\mathrm{r}=1 / 2 \mathrm{~cm}$. Maka dapat dihitung luas permukaan luarnya yaitu $4.1 / 4 \pi$ atau $\pi$, sedangkan volumenya $\frac{1}{3} \pi$.

\section{Balok}

Wajik, makanan ini dicetak dalam ukuran besar kemudian dipotong-potong menjadi bentuk balok yang kecil-kecil. Karena memotongnya tidak dengan diukur secara tepat jadi hasilnya juga ada perbedaan sedikit antara satu dengan yang lainnya, berdasar-kan beberapa yang diukur memiliki ukuran $p$ $=5,1=3 \mathrm{t}=2$. Jika dihitung dengan rumus luas permukaan wajik diperoleh $2(p x t)+2(1 x t)+2(p x l)$ maka diperoleh $62 \mathrm{~m}^{2}$ dan volume balok p x $1 \mathrm{t}$ maka diperoleh $5 \times 3 \times 2$ yaitu $30 \mathrm{~m}^{3}$.

Jadah manten, makanan ini juga dipotong dalam bentuk balok menyerupai bentuk wajik ukurannya tidak sama tergantung potongannya. rata-rata panjang $8 \mathrm{~cm}$, lebar $4 \mathrm{~cm}$ dan tinggi $2 \mathrm{~cm}$. Jika dihitung luas permukaannya maka diperoleh $112 \mathrm{~m}^{2}$ dan volume $8 \mathrm{~cm} \times 4 \mathrm{~cm} \times 2 \mathrm{~cm}=64 \mathrm{~m}^{3}$.

Sawut, makanan ini juga merupakan hasil potongan sehingga membentuk balok-balok dengan ukuran tertentu sesuai dengan hasil potongannya. beberapa ukuran yang diperoleh panjang $7 \mathrm{~cm}$, lebar $4 \mathrm{~cm}$ dan tinggi $3 \mathrm{~cm}$. Jika dihitung luas permukaanya diperoleh hasil $100 \mathrm{~m}^{2}$ dan volume $84 \mathrm{~cm}^{3}$. 
Krasikan, makanan ini juga memiliki pola bentuk seperti balok dari hasil potongan atau irisan pada bentuk dasarnya, yang berbeda bentuk kearah tinggi atau tebalnya dipotong miring seperti trapesium. Adapun ukurang yang diperoleh dengan panjang $6 \mathrm{~cm}$, lebar $4 \mathrm{~cm}$ dan tinggi $3 \mathrm{~cm}$. Jika dihitung luas permukannya diperoleh hasil $108 \mathrm{~cm}^{2}$ dan volume $6 \mathrm{~cm} \times 4 \mathrm{~cm}$ $x 3 \mathrm{~cm}=72 \mathrm{~cm}^{3}$.

\section{Silinder}

Lemper, merupakan jenis makanan yang terbuat dari beras ketan kemudian dibungkus menggunakan daun pisang dan berbentuk menyerupai silinder. Panjang lemper sekitar $6 \mathrm{~cm}$ dengan diameter tengahnya $3 \mathrm{~cm}$. Jika dihitung menggunakan rumus silinder atau tabung maka dapat diketahui volume lemper $\pi \mathbf{r}^{2} \mathbf{t}$ atau $\frac{27}{2} \pi$.

Arem-arem, bentuknya secara fisik hampi sama dengan lemper bedanya kalo jenis makanan ini terbuat dari beras biasa dan ada isi sayuran. Ukurannya sedikit lebih panjang dibanding dengan lemper yaitu $7 \mathrm{~cm}$ dengan diameter tengah $3 \mathrm{~cm}$. Jika dihitung menggunakan rumus silinder atau tabung maka dapat diketahui volume arem-arem $\pi \mathbf{r}^{2} \mathbf{t}$ atau $\frac{63}{2} \pi$.

Beberapa bentuk jajanan pasar lain yang menyerupai silinder atau tabung adalah gethuk lindri, semar mendem, putu ayu, risoles dan kroket.

\section{Kerucut}

Bentuk kerucut juga ditemukan dalam bentuk jajanan pasar misalnya pada jenis clorot. Makanan ini dibungkus menggunakan janur atau daun kelapa seperti kerucut mengecil pada bagian atasnya. Jika diukur panjang atau tinggi dari clorot ini juga agak bervariasi tapi secara umum $10 \mathrm{~cm}$ dengan diameter bawahnya $2 \mathrm{~cm}$. Jika dihitung menggunakan rumus kerucut maka dapat diperoleh volume clorot.

\section{Persamaan Linear}

Pada proses penjualan jajanan pasar seorang penjual pasti akan memperhitungkan keuntungan berapa yang akan dia peroleh. Jika ingin mendapatkan keuntungan maka seorang penjual atau pengrajin jajanan pasar harus mengetahui berapa ongkos produksi dari setiap jenis jajanan pasar tersebut. Berikut adalah hasil wawancara penulis tentang biaya produksi dan harga jual jajanan pasar. 
Tabel 1. Selisih harga produksi dan harga Jual JaJanan Pasar

\begin{tabular}{lccc}
\hline \multicolumn{1}{c}{ Jenis Jajanan } & $\begin{array}{c}\text { Biaya Produksi } \\
\text { (biji) }\end{array}$ & Harga Jual (biji) & Selisih Harga \\
\hline Lemper & 1000 & 1300 & 400 \\
Arem-arem & 1200 & 1500 & 300 \\
Kipo & 300 & 500 & 200 \\
Wajik & 1200 & 1500 & 300 \\
Klepon (5 biji) & $150(750)$ & 1000 & 250 \\
Cenil & 700 & 1000 & 300 \\
Onde-onde & 1000 & 1300 & 300 \\
Semar mendem & 1100 & 1400 & 300 \\
Putu ayu & 900 & 1200 & 300 \\
\hline
\end{tabular}

Berdasarkan harga produksi dan harga jual maka dapat dibuat model persamaan linear. Misalnya saja dari seorang produsen kue jajanan pasar, dalam kasus ini biasanya seorang pembuat jajanan pasar hanya membuat satu atau beberapa jenis jajanan saja, tidak lebih dari 5 buah, kecuali untuk beberapa pengusaha besar.

Contoh, misal Walginah adalah pembuat Jajanan lemper dan arem-arem, dalam satu hari dia dapat membuat dan menjual 250 lemper dan 350 aremarem. Jika biaya produksi dan harga jual sebagaimana yang ada ditabel maka Walginah akan mendapatkan penghasilan setiap harinya adalah.

Misal $\mathrm{x}=$ keuntungan lemper dan $\mathrm{y}=$ keuntungan arem-arem

Bentuk persamaannya

$250 \mathrm{x}+350 \mathrm{y}$

$250(400)+350(300)$

$100.000+105.000$

205.000

Sehingga diperoleh keuntungan Walginah dalam satu hari adalah sebesar Rp $205.000,00$

Aspek matematika yang lain dapat dijumpai dari komposisi perbandingan bahan yang dibuat dalam setiap jenis jajanan pasar dan juga satuan perbandingan bahan yang digunakan misalkan dalam pembuatan aremarem berdasarkan resep bahan yang digunakan adalah: 
Bahan:

500 gram Beras

1 liter Santan dari $1 / 2$ butir kelapa

1 sdt Garam

2 lembar Daun salam

300 gram Daging cincang

300 cc Santan dari 3/4 butir kelapa (santan kental)

3 sdm Minyak untuk menumis

Daun pisang untuk membungkus

Satuan ukuran takaran yang digunakan merupakan bentuk unsur matematika yang diajarkan di SD pada satuan waktu dan pengukuran. Resep ini menggunakan satuan liter, gram, dan cc. Selain itu dalam proses memasaknya juga menggunakan aturan satuan waktu, yaitu agar arem-arem ini matang dengan baik maka harus dikukus minimal 1 jam atau 60 menit, yang dalam matematika dapat juga dinyatakan melalui simbol > 60 menit atau $=60$ menit.

Tabel 2. Aspek-aspek Matematika Pada Jajanan Pasar

\begin{tabular}{|c|c|c|}
\hline $\begin{array}{c}\text { Jenis Jajanan } \\
\text { Pasar }\end{array}$ & Aspek Matematis & $\begin{array}{l}\text { Keterkaitan Budaya atau } \\
\text { Tradisi }\end{array}$ \\
\hline Lemper & $\begin{array}{l}\text { 1. Bentuk Geometris Silinder atau } \\
\text { tabung. } \\
\text { 2. Perkiraan, pada pembuatan } \\
\text { awal hanya diisi seperempatnya } \\
\text { agar ketika matang tidak over. } \\
\text { 3. Dimasak dengan perkiraan } \\
\text { waktu sekitar } 45 \text { menit. } \\
\text { 4. Komposisi perbandingan } \\
\text { bahan-bahan pembuatnya }\end{array}$ & $\begin{array}{l}\text { Mantenan, Mauludan, } \\
\text { Hajatan, rapat, bersih } \\
\text { deso. }\end{array}$ \\
\hline Arem-arem & $\begin{array}{l}\text { 1. Bentuk Geometris Silinder atau } \\
\text { tabung. } \\
\text { 2. Perkiraan, pada pembuatan } \\
\text { awal hanya diisi seperempatnya } \\
\text { agar ketika matang tidak over. } \\
\text { 3. Dimasak dengan perkiraan } \\
\text { waktu sekitar } 45 \\
\text { menit.Bentuknya geometris } \\
\text { silinder atau tabung. } \\
\text { 4. Komposisi perbandingan } \\
\text { bahan-bahan pembuatnya }\end{array}$ & $\begin{array}{l}\text { Mantenan, Hajatan, } \\
\text { Mauludan, rapat, }\end{array}$ \\
\hline
\end{tabular}

JNPM (Jurnal Nasional Pendidikan Matematika) Vol. 2, No. 2, Hal. 217-232

p-ISSN 2549-8495, e-ISSN 2549-4937 @Prodi Pendidikan Matematika Unswagati Cirebon 
Ketupat

Wajik

Klepon

Cenil

Gethuk Lindri

Semar mendem

Putu ayu

Pancong
1. Bentuk geometris belah ketupat

2. Perkiraan, pada pembuatan awal hanya diisi seperempatnya agar ketika matang tidak over.

3. Dimasak dengan perkiraan waktu sekitar 45 menit.

4. Komposisi perbandingan bahan-bahan pembuatnya

1. Komposisi bahan-bahan pembuatnya

2. Perkiraan waktu memasaknya

3. Bentuknya menyerupai lingkaran tidak sempurna

1. Bentuk geometri ruang / balok

2. Perkiraan dalam memotong dari bentuk besar menjadi kotak kecil-kecil

3. Komposisi bahan pembuatnya

4. Perkiraan waktu pembuatannya

1. Bentuk geometris bola

2. Komposisi bahan pembuatnya

3. Perkiraan waktu memasaknya

1. Komposisi bahan pembuatnya

2. Cara menyajikannya dalam tempat dengan jumlah tertentu

3. Komposisi simbol warnawarninya

4. Perkiraan ukuran ketika memotonya.

5. Waktu memasaknya

1. Bentuk potonganya menyerupai silinder

2. Cara penyajiannya dalam satu tempat melingkar

3. Susunan komposisi warnanya

4. Perkiraan waktu memasaknya

5. Menghitung banyaknya lenjeran dalam satu tumpukannya

1. Bentuknya menyerupai silinder

2. Komposisi bahan pembuatnya

3. Perkiraan waktu memasaknya

1. Bentuk geometri seperti roda, ada unsur lingkaran dalam dan lingkaran luarnya

2. Komposisi bahan pembuatnya

3. Perkiraan waktu memasaknya atau 1. Bentuk geometris setengah ellips

2. Waktu memasaknya
Ngapati, Mitoni, Lahiran, Mantenan, bersih deso,

Makanan khas keraton mataram,

Mantenan, bersih deso, hajatan, rapat, mauludan, sesajen.

Hajatan, mantenan, rapat, mauludan, bersih deso.

Hajatan, mantenan, sesajen, mauludan, bersih deso.

Hajatan, mantenan, bersih deso, rapat.

Mantenan, hajatan, rapat, mauludan.

Hajatan, mantenan, rapat, bersih deso, kumpulan, pengajian.

Mantenan, hajatan, bersih deso, rapat, 
Kue lumpur

Onde-onde

Jadah manten

Lupis

Grontol

Sawut

Clorot

Nogosari

Srabi

Krasikan

Kue Cucur
3. Komposisi bahan pembuatnya

4. Perkiraan banyak adonan yang dituangkan ke cetakannya

5. Cara penyajian penjualannya dalam satu plastik diisi 10 kue

1. Bentuk geometri lingkaran

2. Komposisi bahan pembuatnya

3. Waktu memasaknya

1. Bentuk geometri bola

2. Komposisi bahan pembuatnya

3. Waktu memasaknya

1. Bentuk geometri balok dan segiempat

2. Waktu memasaknya

3. Komposisi bahan pembuatnya

4. Perkiraan pembagian memotong dari ukuran besar menjadi ukuran kecil

1. Bentuk geometri segitiga

2. Waktu memasaknya

3. Komposisi bahan pembuatnya

1. Bentuk geometri bola kecil-kecil

2. Lama memasaknya

3. Cara menakar penyajiannya

1. Bentuk geometri balok

2. Cara membagi dari besar menjadi potongan kecil

3. Lama memasaknya

1. Bentuk geometri kerucut

2. Waktu memasaknya

3. Komposisi bahan pembuatnya

1. Bentuk geometri ellips

2. Waktu memasaknya

3. Komposisi bahan pembuatnya

1. Bentuk geometri lingkaran

2. Lama memasaknya

3. Perkiraan adonan pada tiap cetakannya

4. Komposisi bahan pembuatnya

1. Bentuk geometri balok dan trapesium

2. Komposisi bahan pembuatnya

3. Waktu memasaknya

4. Memperkirakan membagi dengan memotong dari besar menjadi kecil-kecil

1. Bentuk geometri lingkaran

2. Waktu memasaknya
Hajatan, mantenan, rapat.

Hajatan, mantenan, rapat.

Hajatan, mantenan, rapat, kenduri, peringatan mauludan, kematian, bersih desa, sesajen, tasyakuran

Tasyakuran, hajatan, mantenan

Tasyakuran,

Hajatan, mantenan

Hajatan, mantenan, sesaji, bersih desa, peringatan kematian, tasyakuran.

Mantenan, hajatan, rapat.

Sesaji, mantenan, peringatan kematian, hajatan, rapat, tasyakuran

Bersih desa, mantenan, tasyakuran, rapat.

Sesaji, mantenan, hajatan, tasyakuran, bersih desa 
3. Komposisi bahan pembuatnya

\begin{tabular}{|c|c|c|}
\hline Donat & $\begin{array}{l}\text { 1. Bentuk geometri lingkaran } \\
\text { 2. Komposisi bahan pembuatnya } \\
\text { 3. Waktu memasaknya }\end{array}$ & $\begin{array}{l}\text { Tasyakuran, bersih desa, } \\
\text { hajatan. }\end{array}$ \\
\hline Bakpia & $\begin{array}{l}\text { 1. Bentuk geometri lingkaran } \\
\text { 2. Waktu memasaknya } \\
\text { 3. Komposisi bahan pembuatnya }\end{array}$ & $\begin{array}{l}\text { Tasyakuran, rapat, } \\
\text { hajatan }\end{array}$ \\
\hline $\begin{array}{l}\text { Kue } \\
\text { semut }\end{array}$ & $\begin{array}{l}\text { 1. Bentuk geometri segi empat dan } \\
\text { lengkung } \\
\text { 2. Komposisi bahan pembuatnya } \\
\text { 3. Cara membagi dari besar } \\
\text { menjadi tipis-tipis } \\
\text { 4. Waktu memasaknya }\end{array}$ & $\begin{array}{l}\text { Tasyakuran, rapat, } \\
\text { hajatan, mantenan. }\end{array}$ \\
\hline Risoles & $\begin{array}{l}\text { 1. Bentuk geometri silinder atau } \\
\text { tabung } \\
\text { 2. Lama waktu memasaknya } \\
\text { 3. Komposisi bahan pembuatnya }\end{array}$ & $\begin{array}{l}\text { Tasyakuran, rapat, } \\
\text { hajatan }\end{array}$ \\
\hline Kue ku & $\begin{array}{l}\text { 1. Bentuk geometri ellips } \\
\text { 2. Lama waktu memasaknya } \\
\text { 3. Komposisi bahan pembuatnya }\end{array}$ & $\begin{array}{l}\text { Hajatan, mantenan, } \\
\text { tasyakuran, rapat, bersih } \\
\text { desa. }\end{array}$ \\
\hline $\begin{array}{l}\text { Bika ambon } \\
\text { ekonomis }\end{array}$ & $\begin{array}{l}\text { 1. Bentuk geometri lingkaran } \\
\text { 2. Komposisi bahan pembuatnya } \\
\text { 3. Waktu memasaknya } \\
\text { 4. Perkiraan adonan dalam } \\
\text { cetakan }\end{array}$ & $\begin{array}{l}\text { Mantenan, sesaji, } \\
\text { tasyakuran, hajatan. }\end{array}$ \\
\hline Apem & $\begin{array}{l}\text { 1. Bentu geometri lingkaran } \\
\text { 2. Komposisi warna warninya } \\
\text { 3. Komposisi bahan pembuatnya } \\
\text { 4. Waktu memasaknya }\end{array}$ & $\begin{array}{l}\text { Sesaji, mantenan, } \\
\text { tasyakuran, bersih desa, } \\
\text { mauludan, peringatan } \\
\text { kematian, peringatan } \\
\text { kelahiran, rapat. }\end{array}$ \\
\hline Kroket & $\begin{array}{l}\text { 1. Bentuk geometri silinder } \\
\text { 2. Komposisi bahan pembuatnya } \\
\text { 3. Waktu memasaknya }\end{array}$ & $\begin{array}{l}\text { Hajatan, tasyakuran, } \\
\text { rapat }\end{array}$ \\
\hline $\begin{array}{l}\text { Kue } \\
\text { nasi }\end{array}$ & $\begin{array}{l}\text { 1. Bentuk geometri lingkaran } \\
\text { 2. Komposisi bahan pembuatnya } \\
\text { 3. Waktu memasaknya }\end{array}$ & $\begin{array}{l}\text { Sesaji, peringatan } \\
\text { kematian, kelahiran, } \\
\text { bersih desa, hajatan, } \\
\text { mantenan, mauludan, } \\
\text { tasyakuran. }\end{array}$ \\
\hline Carabikang & $\begin{array}{l}\text { 1. Bentuk geometri lingkaran } \\
\text { 2. Waktu memasaknya } \\
\text { 3. Komposisi bahan pembuatnya }\end{array}$ & $\begin{array}{l}\text { Mantenan, tasyakuran, } \\
\text { bersih desa, mauludan. }\end{array}$ \\
\hline
\end{tabular}

\section{Kesimpulan dan Saran}

Berdasarkan pada kajian terhadap bentuk jajanan pasar yang berada di Wilayah Yogyakarta diperoleh beberapa unsur etnomatematika diantaranya

JNPM (Jurnal Nasional Pendidikan Matematika) Vol. 2, No. 2, Hal. 217-232

p-ISSN 2549-8495, e-ISSN 2549-4937 @Prodi Pendidikan Matematika Unswagati Cirebon 
unsur geometri bidang dan geometri ruang seperti lingkaran, elips, segitiga, segiempat, dan trapesium kemudian untuk geometri ruang ada bentuk bola, silinder atau tabung, balok dan kerucut. Selain bentuk geometri juga ditemukan aspek ekonomi dalam sistem penjualan jajanan pasar yang dalam hal ini dapat dikaitkan pada perhitungan persamaan linear dangan variabel misalnya dalam menghitung keuntungan maksimal yang diperoleh seorang pembuat atau penjual Jajanan pasar dengan bentuk ax + by $=c$. Selain itu bentuk komposisi campuran bahan pokok, satuan setiap bahan yang digunakan dan lama waktu memasaknya merupakan bagian dari satuan waktu dan ukuran dalam matematika.

Penelitian sebenarnya masih belum mendalam dan jika dilanjutkan untuk digali lebih mendalam masih sangat banyak unsur matematika yang dapa ditemukan kembali. Sehingga penulis menyarankan untuk menggali kembali proses penemuan etnomatematika pada jajanan pasar misalnya dikaitkan dengan makna filosofis setiap bentuknya dengan logika matematika atau dengan unsur yang lain.

\section{Daftar Pustaka}

Aditya, W. U. ( 2016). Pengembangan Ensiklopedi Makanan Tradisional Daerah Istimewa Yogyakarta, Skripsi, PGSD FKIP Universitas Sanata Dharma Yogyakarta.

Amelia, Y. (2016). Studi Eksplorasi Etnomatematika pada Lingko Lodok dalam Budaya Masyarakat Manggarai, Skripsi FKIP USD Yogyakarta.

Arum, K. (2013). Penggunaan Istilah Makanan dan Jajanan Tradisional pada Masyarakat di Kabupaten Banyuwangi, Publika Budaya Volume 1(1), Fakultas Sastra Universitas Jember Jawa Timur.

Bishop, Alan J. 1988. Mathematical Enculturation: a cultural perspective on Mathematics Education, D. Reidel Publising Company, Dordrecht, Holand. http://www.csus.edu/indiv/o/oreyd/acp.htm files/abishop.htm,diakses pada 19 November 2017.

Cristi, M. (2016). Desain Pembelajaran Matematika dengan Pendekatan Etnomatematika pada Materi Nilai Tempat kelas 2 SD. Jurnal LEMMA Vol III No. 1, STKIP PGRI Sumatera Barat. 
D'Ambrosio, U dan Rosa, M. (2008). A. dialogeu with ubiratan D'Ambrosio:a Brazilian conversation about ethnomathematics. Revista Latinoamericana de Etnomatematica, Vol I No. 2.88-110.

David Slamet, S. (2015). Studi Etnomatematika Kraton Yogyakarta, Penelitian Ilmu Pendidikan, PPS UNY Yogyakarta.

Gerdes, P. (1988). On culture, geometrical thinking and mathematics education. Educational studies in mathematics. 19(3):13-162.

Hiebert,J.\&Carpenter, T.P.(1992). Learning with understading. Dalam D.G. Grouws(Ed),Handbook of research on mathematics reaching andlearning. New York:Macmillan.

Herusatata dan Budiono, (1984). Simbolisme dalam Budaya Jawa. Yogyakarta: Hanindita

http://candracahyono.blogspot.com/2012/11/pengertian-budaya-jawa.html

Koentjaraningrat, (1980). Sejarah Teori Antropologi 1. Jakarta:UI Press

Marzuki. (2015). Tradisi dan Budaya Masyarakat Jawa dalam Perspektif Islam, Jurnal FIS UNY Yogyakarta.

Nanik, H. (2012). Kearifan Lokal Bagian Budaya Jawa, Jounal Magistra ISSN 0215-9511, FKIP UNWIDHA Klaten.

Pujiati dan Sigit. (2009). Pembelajaran Pengukuran luas bangun datar dan Volum bangun ruang di SD, Modul Matematika SD Bermutu, PPPPTK Yogyakarta.

Yoanna, K. ( 2017). Kajian Etnomatematika terhadap Tradisi Pernikahan Yogyakarta oleh Masyarakat di Kecamatan Minggir Sleman Yogyakarta dalam rangka Penentuan aspek-aspek Matematis yang dapat digunakan dalam Pembelajaran Matematika di SMP. Thesis FKIP USD Yogyakarta. 